\title{
Transition: getting it right for young people
}

\author{
Alison Jordan and Janet E McDonagh
}

Transition is a key aspect of adolescent healthcare, irrespective of the presence or absence of chronic illness and/or disability. All young people will hopefully make the transition from childhood to adulthood and, along the way, move from the family home to live independently, from school to further education and/or training and/or work, and from paediatric to adult services including healthcare. Many young people make these transitions successfully. Some, however, will find them difficult for various reasons and this latter group potentially includes young people with chronic illnesses and/or disabilities.

Transition is a multi-faceted, active process that attends to the medical, psychosocial and educational/vocational needs of adolescents as they move from child- to adult-centred care. The principles have been detailed in recent Department of Health guidance, ${ }^{1}$ echoing core standard four of the National Service Framework (NSF) for Children, Young People and Maternity Services which specifically relates to young people up to the age of 19 years. ${ }^{2}$ Development and provision of transitional care for the increasing numbers of young people with chronic illness and/or disability surviving into adulthood is a major challenge for the NHS in this century. Transition is therefore of concern and relevance to clinical practitioners from a wide range of disciplines and healthcare commissioners in both paediatric and adult sectors.

\section{The evidence base for transition}

Although there are many compelling arguments that transitional-care service provision in the UK needs to be developed, many practitioners and policymakers are unsure as to what should be done and/or how to implement such changes in practice. To date there have been no true randomised control trials, with the majority of studies being descriptive $(35 \%)$ or based on user accounts (34\%) and only $14 \%$ being true evaluations of services. ${ }^{3}$ Results from a large multicentre study of an evidence-based coordinated transitional care programme in rheumatology has reported significant improvements at 6 and 12 months for adolescents and their parents compared to baseline in terms of health-related quality of life, knowledge, satisfaction and vocational readiness. ${ }^{4}$

\section{'Nothing about us, without us'}

Recognition of the rights of young people to be heard is enshrined in the 1989 UN Convention on the Rights of the Child, in which Article 12 confirms the fundamental right of the young person to express his or her views in all matters affecting the young person. The literature is very persuasive of the need for improvement in transition in the UK from the young person's perspective. ${ }^{3,5}$ Young people have also been clear about their desire to be involved in planning and/or goal-setting with their healthcare team. ${ }^{6}$ It is therefore important that health professionals engage the young people themselves as well as their parents when providing such care and developing transition services.

\section{Increasing numbers and complexity}

In the UK, $10-20 \%$ of adolescents have a significant ongoing healthcare need related to a chronic health condition. With rapidly evolving medical technology and improvements in therapies and medical care, there are increasing numbers of young people with chronic illnesses and/or disabilities surviving into adulthood where previously they died in childhood. Such evidence supports the need for both age and developmentally appropriate service development for these young people in addition to training for the adult services which may not have previously encountered young people with these 'new' conditions. One per cent of all newborn babies have congenital heart disease. Forty years ago, 70\% of such children would have died before the age of 10 years. In $2005,85 \%$ will survive into adulthood. ${ }^{7}$ Since its first recognition as a disease entity in the 1930s, cystic fibrosis has improved from a 70\% one-year mortality rate such that the median survival is now predicted to be 40 years for a child born in the 1990s. ${ }^{8}$ Around $70 \%$ of young people with cerebral palsy will survive into adulthood, ${ }^{9}$ while more than $50 \%$ of children with spina bifida ${ }^{10}$ and $53 \%$ of boys with muscular dystrophy will survive to 25 years. ${ }^{11}$ Increased survival, however, has not come without cost. Late asymptomatic shunt failure in adults with spina bifida, hydrocephalus and shunts occur primarily in early adolescence (13\%), then $4 \%$ per year thereafter, with associated chronic morbidity and/or death. ${ }^{12}$ Over a third of patients with a renal transplant trans-
Alison Jordan MRCP, Specialist Registrar in Adolescent Rheumatology, Birmingham Children's Hospital, Birmingham

\section{Janet E} McDonagh MD, FRCP, Arthritis Research Campaign Clinical Senior Lecturer in Paediatric and Adolescent Rheumatology, Institute of Child Health, University of Birmingham, Birmingham

This conference was held at the Royal College of Physicians on 23 March 2006 and was organised by the Department of Health 
ferred to adult nephrologists lost their graft within 36 months of transfer. $^{13}$

\section{Looking outside of the health box}

'I think doctors should focus more on how to live with the condition.' ${ }^{14}$

Several authors have reported the perceived lack of interest by health professionals in the wider impact of chronic illness on the life of young people. ${ }^{15,16}$ Health professionals need to look beyond health and consider the impact of the chronic illness in terms of the psychosocial and cognitive development of the young person. Reflecting this, the range of information needs requested by young people is wide, extending well beyond the medical aspects of the condition. ${ }^{6,15-17}$ The delivery of such information needs to be effective, age and developmentally appropriate and honest, the latter reported to be particularly valued by young people. ${ }^{14,15,18}$

\section{Skills to survive and thrive!}

Information provision is one component of the wider skills training of young people during transition. Young people are, after all, the 'new users of health services', the services previously accessed by their parents/caregivers on their behalf. Skills training in self-advocacy for young people with chronic illness

\section{Conference programme}

I Welcome to young people Professor Dame Carol Black

I The research evidence for transition services Dr Janet McDonagh

I The new areas of transition where children and young people are surviving into adulthood

Professor Terence Stephenson

- Social and psychological perspectives on transition Dr John Coleman

Iransitions: getting it right for young people Young people's video

I Transition or transfer - profile of the Good Practice Guidance Professor Sir David Hall

I Support for Good Practice Guidance - jointly supported by Royal Colleges and the Department of Health Professor Dame Carol Black and Professor Sir Alan Craft

International perspectives on transition - Australia, Canada, USA Live panel discussion: Dr Russell Viner, Dr Miriam Kaufman, Professor Susan Sawyer and Professor Bob Blum

I Minister's address Rt Hon Liam Byrne, MP

I Challenges for the future - what the Department of Health and the NHS should do to further support the delivery for young people Dr Sheila Shribman, Dr Mary Armitage, Dr Janet McDonagh and Professor Sir Alan Craft and/or disability is integral to transition and reflects the resilience framework integral to adolescent health - to survive and thrive! Examples of self-advocacy in healthcare include:

- feeling confident to see the health professional independent of their parents when the young person so chooses

- accessing healthcare independently

- being aware of their own health

- understanding their own medical condition and/or therapy

- self-managing their condition.

\section{Transition - a multidisciplinary process}

'For transition to work, we all need to work together as a team.'18

Although there is no robust evidence to support one type of model over another, transitional care is a multidisciplinary concern and 'not just the doctor's responsibility', as stated by one of the young people at the conference. ${ }^{14}$ Transition is by definition a process with transfer being a single event within transition which begins in paediatric care and is completed when the young person is actively participating in adult care. A key principle of transition is planning. In a 10-year audit of admissions of young adults aged 18 years and over to a major Australian paediatric hospital, 51\% of surgical inpatients and $28 \%$ of medical inpatients had no documented plan for transition to adult care. ${ }^{19}$ When individualised transition plans, developed with the young people and with their parents respectively, were implemented in a programme of transitional care, they were successfully completed by $95 \%$ and $92 \%$ of adolescents and their parents respectively, successfully identifying their needs. ${ }^{20}$ Various other templates have been reported ${ }^{21}$ although not formally evaluated.

Various transition models have been described in the literature ${ }^{3,22,23}$ but only a few have been formally evaluated. ${ }^{4,22}$ The young adult team approach has been advocated by several authors, ${ }^{17,22,23}$ particularly for young people with physical disability 22,23 or chronic illnesses where the adult population is biased towards the older age groups, eg diabetes. ${ }^{17}$

\section{Primary care and transition}

The general practitioner (GP) is an obvious candidate for a key worker role in transition as he/she can potentially provide continuity of care for such young people. Although clearly advocated in the NSF, ${ }^{2}$ it is unclear as to how this role is currently perceived and practised by the majority of GPs. GPs are the most likely to provide the patient with their only medical continuity during the period of transfer and are important in encouraging skills for appropriate healthcare utilisation. Furthermore, primary care teams may be particularly important for those patients who choose not to attend specialist adult services by allowing some opportunity for monitoring and addressing physical health and psychosocial well-being. It is important, however, that primary care is involved in the care partnership prior to discharge from hospital care, particularly with complex disease and/or disability. 


\section{Parents and transition}

The Children's NSF advocates the need for 'services to seek to support parents in particular providing information and advice on how they can appropriately support their child's transition to adulthood. ${ }^{2}$ Factors associated with resilience for young people with chronic illness and/or disabilities have been reported to include family and parent support without over-protectiveness. ${ }^{24}$ Getting the balance right is difficult for parents of any teenager, let alone those with the added challenge of chronic illness and/or disability. Furthermore, whilst healthcare providers advocate for the young person, they must remain inclusive of the parents. Parents have suggested ways for health professionals to help them to become better advocates for their children. ${ }^{15}$ These include professionals actively involving young people during consultations and maintaining continuity in professionals in order to build trust. With these in place, parents thought they would be able to gradually withdraw from their primary role in triadic consultations. They also proposed, however, that this would provide time for their own needs to be met with respect to parenting an adolescent with a chronic illness and/or disability. ${ }^{15}$ Such service provision has obvious resource allocation in terms of clinic space and/or time in addition to staffing levels, particularly for those practitioners not working within a multidisciplinary team.

\section{Global perspective}

Transitional care is just one component of adolescent healthcare which is still in its infancy in the UK, unlike in North America and Australia, where adolescent health is a recognised specialty, distinct from paediatric and adult medicine. There is much to learn and share from international experience, particularly with respect to information about resources and transition (Table 1). Although the philosophy of transition has been accepted internationally for over a decade, the challenges of translating policy into practice remain. Legislation, policies and policy guidance do not guarantee change or improvements. Despite a national consensus statement, ${ }^{25}$ a US-based study of 4,332 young people with special healthcare needs showed that half had not discussed transition and of those who had, only $59 \%$ had a plan and only $42 \%$ had discussed transfer to adult care. ${ }^{26}$

\section{Training and transition}

The current background of limited, formal training opportunities in adolescent health training for both paediatric and adult care providers ${ }^{27,28}$ will impact on delivery of transitional care in the UK. Although availability of professionals knowledgeable in transitional care was considered to be best practice by users and providers alike, it was felt to be only feasible in a few UK centres. ${ }^{29}$ Development of training at both undergraduate and postgraduate levels across disciplines will be imperative if transitional care developments are to be effective.

\section{Transition and today's NHS}

Lack of training is one of several potential barriers to provider involvement in transition which also include attitudinal barriers, lack of time and money and perceived lack of applicability. There are few studies reporting an economic cost evaluation of specific models although Bent reported that a young adult team approach costs no more than ad hoc services for young people with a physical disability and was also associated with increased participation in society. ${ }^{22}$ Further research is needed in this area and imaginative consideration of how available monies can be shared between specialties and services, acknowledging the non-categorical nature of many transitional care issues.

\section{Conclusions and a way forward}

Transitional care, as with the rest of adolescent health, is now firmly on the health agenda. Further successful development in this area will require 'a shift in attitude and a bit of passion' from health professionals ${ }^{14}$ along with mutual respect and effective collaboration between paediatric- and adult-care providers, across disciplines and professions in health and across the agencies representing education, social services, youth services and the voluntary sector. As Toyah, one of the young advisors to

Table 1. Examples of online resources for transition.

\begin{tabular}{lll}
\hline Country of origin & Transition & Training in adolescent health including transition \\
\hline $\begin{array}{l}\text { UK and Europe } \\
\text { Europe }\end{array}$ & $\begin{array}{l}\text { www.dh.gov.uk/transition } \\
\text { www2.rcn.org.uk/cyp/resources/a-z_of_resources/adolescent_health }\end{array}$ & $\begin{array}{l}\text { www.tsa.uk.com } \\
\text { www.transitioninfonetwork.org.uk } \\
\text { www.dreamteam-uk.org } \\
\text { www.transitionpathway.co.uk/ }\end{array}$ \\
& www.rch.org.au/transition & \\
Australia & www.door2adulthood.com & www.cps.ca/englishprodev/NTIAH/index.htm \\
Canada & http://hctransitions.ichp.ufl.edu/ & www.usc.edu/adolhealth/ \\
USA & http://depts.washington.edu/healthtr/index.html \\
&
\end{tabular}


the conference, says in the concluding frames of the conference DVD, 'we have to get transition right' so that it becomes a positive, enriching experience for all young people with chronic illness and/or disability. ${ }^{14}$

\section{Acknowledgements}

Our thanks to all the young people and professionals who took part in both the organisation of the conference as well as all those who participated on the day. JEMcD is an Arthritis Research Campaign-funded Clinical Senior Lecturer in Paediatric and Adolescent Rheumatology.

\section{References}

1 Department of Health. Transition: getting it right for young people. Improving the transition of young people with long-term conditions from children's to adult health services. London: DH, 2006.

2 Department of Health. National Service Framework for children, young people and maternity services. London: DH, 2004. www.dh.gov.uk

3 While A, Forbes A, Ullman $\mathrm{R}$ et al. Good practices that address continuity during transition from child to adult care: synthesis of the evidence. Child Care Health Dev 2004;30:439-52.

4 McDonagh JE, Southwood TR, Shaw KL. The impact of a coordinated transitional care programme on adolescents with juvenile idiopathic arthritis. Rheumatology (Oxford) 29 June, 2006 [Epub ahead of print] (in press).

5 Beresford B. On the road to nowhere? Young disabled people and transition. Child Care Health Dev 2004;30:581-7.

6 Scott L, Vallis M, Charette M, Murray A, Latta R. Transition of care: researching the needs of young adults with type 1 diabetes. Can J Diabetes 2005;29:203-10.

7 Somerville J. Grown-up congenital hearts: good care is the profession's responsibility. Br J Cardiol 1998;5:570-84.

8 Elborn JS, Shale DJ, Britton JR. Cystic fibrosis: current survival and population estimate to the year 2000. Thorax 1991;46:881-5.

9 Stevenson CJ, Pharoah POD, Stevenson R. Cerebral palsy - the transition from youth to adulthood. Dev Med Child Neurol 1997;39:336-42.

10 Hunt GM, Poulton A. Open spina bifida: a complete cohort reviewed 25 years after closure. Dev Med Child Neurol 1995;37:19-29.

11 Eagle M, Baudouin SV, Chandler C et al. Survival in Duchenne muscular dystrophy: improvements in life expectancy since 1967 and the impact of home nocturnal ventilation. Neuromuscul Disord 2002; 12:926-9.

12 Tomlinson P, Sugarman ID. Complications with shunts in adults with spina bifida. BMJ 1995;311:286-7.

13 Watson AR. Non-compliance and transfer from paediatric to adult transplant unit. Pediatr Nephrol 2000;14:469-72.

14 Department of Health. Transition: getting it right. A film by Greg, Toyah, Craig, AJ and Chris. London, DH, 2006. DVD. Please contact MBChildrens-Health@dh.gsi.gov.uk for further information.
15 Shaw KL, Southwood TR, McDonagh JE on behalf of the British Paediatric Rheumatology Group. User perspectives of transitional care for adolescents with juvenile idiopathic arthritis. Rheumatology (Oxford) 2004;43:770-8.

16 Beresford B, Sloper P. Chronically ill adolescents' experiences of communicating with doctors: a qualitative study. J Adolesc Health 2003; 33:172-9.

17 Dovey-Pearce G, Hurrell R, May C, Walker C, Doherty Y. Young adults' (16-25 years) suggestions for providing developmentally appropriate diabetes services: a qualitative study. Health Soc Care Community 2005; 13:409-19.

18 Klostermann BK, Slap GB, Nebrig DM, Tivorsak TL, Britto MT Earning trust and losing it: adolescents' views on trusting physicians. J Fam Pract 2005;54:679-87.

19 Lam PY, Fitzgerald BB, Sawyer SM. Young adults in children's hospitals: why are they there? Med J Aust 2005;182:381-4.

20 McDonagh JE, Southwood TR, Shaw KL. Growing up and moving on in rheumatology: development and preliminary evaluation of a transitional care programme for a multicentre cohort of adolescents with juvenile idiopathic arthritis. J Child Health Care 2006;10:22-42.

21 Royal College of Nursing. Adolescent transition care: guidance for nursing staff. London: RCN, 2004. www.rcn.org.uk

22 Bent N, Tennant A, Swift T et al. Team approach versus ad hoc health services for young people with physical disabilities: a retrospective cohort study. Lancet 2002;360:1280-6.

23 Chamberlain MA, Kent RM. The needs of young people with disabilities in transition from paediatric to adult services. Eura Medicophys 2005;41:111-23.

24 Werner EE, Smith RS. Overcoming the odds: high risk children from birth to adulthood. Ithaca: Cornell University Press, 1992.

25 American Academy of Pediatrics, American Academy of Family Physicians, American College of Physicians-American Society of Internal Medicine. A consensus statement on health care transitions for young adults with special health care needs. Pediatrics 2002;110:1304-6.

26 Lotstein DS, McPherson M, Strickland B, Newacheck PW. Transition planning for youth with special health care needs: results from the National Survey of Children with Special Health Care Needs. Pediatrics 2005;115:1562-8.

27 Royal College of Paediatrics and Child Health. Bridging the gap: health care for adolescents. London: RCPCH, 2003. www.rcpch.ac.uk

28 McDonagh JE, Minnaar G, Kelly KM, O’Connor D, Shaw KL. Unmet education and training needs in adolescent health of health professionals in a UK children's hospital. Acta Paediatr 2006;95:715-9.

29 Shaw KL, Southwood TR, McDonagh JE. Transitional care for adolescents with juvenile idiopathic arthritis: a Delphi study. Rheumatology (Oxford) 2004;43:1000-6. 